\title{
Discussion and inquiry: A Deweyan perspective on teaching controversial issues
}

\begin{abstract}
There is a steady line of academic discourse around the topic of controversial issues and how to approach them in and through education. In this line of discourse, discussion is widely seen as a primary method of democratic education that is especially suitable to foster its major educational aims, such as tolerance, reciprocal respect or political autonomy. The aim of this contribution is to show that the widespread emphasis on the educational and political value of discussions as a way to handle controversial issues in education can be problematic and one-sided. It is argued that the focus on discussions sometimes tends to be interpreted as a 'magic bullet' to all different sorts of controversies, without sufficient inquiry into the details that make up the controversy. This uniform solution threatens to downplay and underestimates other relevant components which are essential for the intelligent handling of controversial issues, such as practices of inquiry. Instead of questioning the political value and central educational role of discussing controversial issues tout court, the contribution points out some of the blind spots of the current debate and thereby aims to broaden the spectrum of theoretical and practical perspectives on how to approach controversial issues in education.
\end{abstract}

\section{Keywords}

Controversial issues, inquiry, discussion, John Dewey, democratic education

\section{Introduction}

There is a steady line of academic discourse around the topic of controversial issues and how to approach them in and through education. In this line of discourse, discussion is widely seen as a primary method of democratic education that is especially suitable to foster its major educational aims, such as tolerance, reciprocal respect or political autonomy (see, for instance: Hess 2009; Hess and MacAvoy 2015; Yacek 2018; Pace 2021). The aim of this contribution is to note that the widespread emphasis on the educational and political value of discussions as a way to handle controversial issues in education can be problematic and may lead to one-sided practices. We argue that the focus on discussions sometimes tends to be interpreted as a 'magic bullet' to all different sorts of controversies, without sufficient inquiry into the details that make up the controversy. This uniform solution threatens to downplay and underestimates other relevant components which are essential for the intelligent handling of controversial issues, such as practices and habits of inquiry. Our aim is not to question the political value and central educational role of discussing controversial issues tout court, but rather to point out some of the blind spots of the current debate and thereby to broaden the spectrum of theoretical and practical perspectives on how to approach controversial issues in education.

Our argument proceeds in three steps: As a start we first provide a brief reconstruction of the pivotal role that discussions play in the context of deliberative conceptions of democratic education and of some of the problems that are associated with this strong educational and political focus on the value and practice of discussion (2.). Secondly, we engage with the controversy over controversial issues in the philosophy of education and especially with the question how teachers shall practically deal with controversial issues in the classroom. We argue that the search for a single and exclusive approach to practically deal with controversial issues (e.g., more or less directively guided discussion), may lead to underestimating the complexity and diversity of the 
relevant educational challenges and might ignore alternative educational approaches to controversial issues, other than discussion (3.). In the fourth section, we outline a pragmatist approach to democratic inquiry, based on the philosophy of John Dewey. We argue that Dewey's demand for the use of a scientific method in making the most of intelligence embedded in communities and their members can serve as a complementary approach to pursue the same aims that are being pursued through deliberative approaches (4.) In the fifth section we take a look at inquiry as an approach for dealing with controversial issues in education. (5).

\section{Democratic education, deliberative democracy and classroom discussion}

Deliberative democratic theory assumes that a vibrant democratic culture and a critical public sphere are essentially dependent on suitable forms of democratic education. On this view, democratic education plays the central role of enabling informed participation of citizens in collective processes of democratic will-formation and self-determination. In this theoretical framework, democratic education can be understood as the cultivation of the capacities, dispositions and attitudes necessary to engage in political debates in an appropriate and informed way, as well as an initiation into the practice of giving and asking for reasons in contexts of democratic deliberation. In line with this, much "advocacy for discussion in democratic education emerges from the belief that a healthy democracy requires necessary and ongoing political discussion among citizens" (Hess 2009: 29). Especially practices of debating controversial political issues in schools and classrooms is regarded as one of the central practical means of realizing the aims of democratic education (Hess 2009; Hess and McAvoy 2015) by fostering rational deliberation and communicative interaction with others as well as by helping students to learn to live with disagreement and dissent (Reichenbach 2000a). As Hess and McAvoy put it: "Mastering the ability to talk across political and ideological differences helps create an informed citizenry - an essential component of a democratic society - by teaching students to weigh evidence, consider competing views, form an opinion, articulate that opinion, and respond to those who disagree" (2015: 5). A variety educational practices and methods can be subsumed under the notion of 'discussion' (such as, for instance, Socratic teaching methods, entirely 'open' discussions or more guided discussions) and different, more or less demanding standards are employed to determine the purposes and quality of discussions (or, in cases of normatively charged concepts, what counts as a discussion in the first place) as well as the difference between discussions as a more general category and specific types of discussions, such as 'deliberations'. According to David Bridges (1979), for instance, people are engaged in a discussion, if

a) they are putting forward more than one point of view upon a subject;

b) they are at least disposed to examine and be responsive to the different points of view put forward; with

c) the intention of developing their knowledge, understanding and/or judgment on the matter under discussion (16).

One way to draw the distinction between discussion and deliberation (as a more specific type of discussion) is to argue that while the content and purpose of discussions are focused on the expression and engagement with different types of views in order to foster mutual understanding, deliberations are dealing with shared problems that require students to consider the question "How should we live together?'" (Hess and McAvoy 2015: 5, referring to a distinction of: Parker 2003). Thus, when dealing with controversial issues in educational contexts not any type of discussion will be suitable, but it depends both on the quality of discussion as well as on the way discussions are facilitated by the teacher. There is widespread consensus in the literature that discussions of controversial issues are a quite demanding and often also risky enterprise, which has to be prepared by teachers in an appropriate way in order to be successful (for instance, by ensuring a discussionfriendly classroom climate and that all students are able to participate in an appropriate way; Pace 
2021). There is also a basic consensus among advocates of deliberative conceptions of democratic education, that the initiation into discursive practices and debates is the ideal and arguably also the most 'democratic' (in the sense of ideals of deliberative democracy) way to educate for democracy and to deal with the many conflicts that pervade democratic life. ${ }^{1}$ Discussion is considered as the democratic practice par excellence, an "essential part of learning to live in a democracy" (Hess and McAvoy 2015: 5; with reference to Hess 2009), which is both instrumentally and intrinsically valuable for the realization of central aims of democratic education. Within this theoretical framework the practice of discussion is not only regarded as intrinsically valuable in itself (Hess 2002), but also attributed a variety of educational and political functions, which are also justified by corresponding empirical assumptions concerning the effects of discursive educational formats (for example, with respect to the development of tolerance and respect as well as the acceptance of pluralism etc.) (Hess and McAvoy 2015). ${ }^{2}$ Even though a variety of studies indicate that debating controversial issues indeed have positive effects on central aims of democratic education such as tolerance and civic engagement (Hess 2009) ${ }^{3}$, one nevertheless has to be careful not to overgeneralize these findings - especially due to limited knowledge about specific causal factors that may be responsible for the relevant results. As Hess puts it with reference to Hahn (1996): "educators use many approaches to discussion, and virtually all of them are embedded in a course of study that includes a number of other components as well. Thus, measuring the influence that discussion of controversial issues has on particular outcomes is difficult" (Hess 2009: 33). Apart from these and other methodological difficulties in singling out particular factors and their specific - short and long-term - effects on the realization of the aims of democratic education (see also: Gronostay 2019), there are also other reasons for being skeptical concerning generalized attributions of values and functions to particular dialogical educational formats (intrinsically or instrumentally valuable and/or functional with respect to educational aim X). Critics of deliberative democracy, for instance, emphasize problematic consequences of collective deliberation processes, such as more, rather than less polarization as effects of heated political discussions (Brennan 2017; Talisse 2019). Along these lines also the educational and political aims that discussions are supposed to further are interpreted as more ambivalent than by defenders of deliberative ideals. The assumed intrinsic value of political participation and civic engagement, for instance, can be questioned in cases, where agents participate in the name of questionable political goals (Reichenbach 2020a). In such cases, where discussions can have a variety of non-intended side effects, the formula 'more discussions of controversial issues $=$ more participation $=$ better for democracy' lacks plausibility, at least in this generalized form.

Deliberative conceptions are also criticized for being based on unrealistic expectations regarding the preconditions and possibilities of discursive participation (Reichenbach 2020a) and rational argumentation (Huhtala and Holma 2019). Even if one grants that deliberative democracy itself is a long-term educational project that aims to realize its own preconditions also via the educational system, it is nevertheless important to note that the capacities and attitudes necessary to contribute to a discussion in an informed and appropriate way cannot entirely be created by discussions themselves, but have to be fostered primarily by other educational means. This is one of the reasons why the ideal to discuss controversial issues openly in the classroom may in some contexts constitute a very demanding and in some cases perhaps also an overly demanding ideal of citizenship that overburdens students with discursive tasks which they are not yet able to handle

\footnotetext{
${ }^{1}$ Englund as a defender of a deliberative conception of democratic education, however, argues that despite a general focus on discussions, "(...) this does not mean that educational practice should without exception be concerned with deliberative communication - it is a question for the teacher, in collaboration with the students, to judge the suitability of deliberative communication in any given context" (Englund 2006: 513).

2 The following two sections are partly based on the approach and argumentation developed in: Drerup (2021).

${ }^{3}$ While it is true that empirically discussion of controversial issues in the classroom often tends to have only a minor role (Hess 2002), it does not follow from this that discussion is always an educationally suitable approach to deal with these issues.
} 
appropriately. Moreover, the ideal of rational deliberation is certainly laudable and worth defending, its practice is - especially when it comes to controversial and polarizing issues - in many cases obviously far less than rational, also due to the important, but often neglected role of emotions in political discussions in and outside of the classroom (Huhtala and Holma 2019) as well as the ubiquity of the possibility of misunderstandings (Reichenbach 2020b). ${ }^{4}$

Another problem in the debate about the proper place of discussions in educational constellations is not only that the relevant conceptions (of discussion, dialogue, communicative action etc.) are in many cases highly normatively charged educational and political ideals, but also that the debate is prone to operate with moralized dichotomies (dialogue = reciprocity, equality, symmetry, active students etc. $=$ good vs. monologue $=$ hierarchical, asymmetrical, technological, passive students etc. = bad) $($ Kvernbekk 2010: 969). This tendency to focus on the alleged moral superiority of dialogues draws an overly simplistic picture of educational constellations, by hiding normatively relevant differences concerning different forms of more dialogical and monological approaches to education as well as problematic facets of dialogical and positive qualities of monological teaching styles. Monological instruction styles can, for instance, provide spaces for students to become highly 'active' and arguably also free, because there is a certain "distance between sender and receiver" (Kvernbekk 2010: 975). Conversely, also the demand for reciprocity and the expectation to respond in dialogues can become oppressive. These normative dichotomies, moreover, indicate that we would have to choose between both forms of educational orientation in an either-or fashion and downplays their factual - and potentially valuable - copresence in educational constellations.

These are some of the reasons why - even though we agree with central aspects of the theoretical framework of deliberative democratic education ${ }^{5}$ and it's normative aims - we are more skeptical concerning the prominent role that classroom discussions of controversial issues play in this framework to realize these aims. Given the problems outlined above it seems both rather questionable to assign intrinsic value to 'discussions as such' and to assume that discussions is a universally relevant educational approach to achieve the aims of democratic education. There is a certain risk that discussions tend to be considered as a type of 'magic bullet' that may be used to deal with all sorts of political problems, also in such cases where this may not be educationally appropriate. Instead, in what follows we will argue that it is more plausible to regard discussions as one important educational way of dealing with controversies in educational contexts, and not as a default option.

\section{The controversy over controversial issues: Beyond discussion}

The 'controversy over controversial issues' in the philosophy of education (see: Warnick and Smith 2014; Gregory 2014; Zimmermann and Robertson 2017; Levinson and Fay 2019; see for the

\footnotetext{
${ }^{4}$ Discussion as an educational approach thus falls prey to much of the criticism that has mostly been presented in debates around deliberative democracy. Suffices to say that assuming equality between participants as a necessary prerequisite does not mean that participants in fact have equal opportunities for participation, and thus deliberation (and discussion) cannot avoid the common pitfalls of group dynamics or oppressive power relations of societies, and the result may just amplify the existing evils (see Sanders 1997). Pedagogical constellations - even in supposedly egalitarian democratic classrooms - remain asymmetrical constellations in which the ability to articulate one's own interests and assert them discursively usually are unequally distributed, both between teachers and students and among students themselves (Hess and McAvoy 2015). The ideal of symmetrical communication and equal participation which underlies deliberative conceptions of democratic education is not only in tension with the political and epistemic authority of the teacher. There is also the danger that these ideals may be instrumentalized by teachers as a means to delegate educational and political responsibility to their students, also in such cases where an open discussion may not be suitable.

5 This is also due to the fact that there are certain affinities between Deweyan conceptions of democratic education and deliberative conceptions and Hess and McAvoy (2015) also place their approach partly in the tradition of Dewey's conception of democratic education. See also: Englund (2006).
} 
German debate: Widmaier and Zorn 2016) is essentially concerned with three interrelated questions: What should be taught controversially in the classroom? How should controversial issues be taught and discussed in the classroom? Why should we teach controversial issues? All three questions, the 'what', the 'how' and the 'why' of teaching controversial issues in the classroom, are themselves the object of an ongoing controversy. The question how controversial issues should be taught can hardly be answered without reference to both the debate about adequate criteria to distinguish controversial from non-controversial issues as well as the debate on the question why controversial issues should be taught in schools in the first place are. Therefore, we briefly outline our take on the 'what' and the 'why' question, before focusing on the debate about different practical educational approaches to teaching controversial issues as well as the role that different forms of discussion play in these approaches.

One of the widespread, but nevertheless controversial assumptions in the debate about the what question is that all potentially controversial issues should be taught non-directively. This means that they should be discussed openly without intent to compel belief in any one position in the controversy. Otherwise the teacher may be charged with the illegitimate imposition of a particular political opinion on students, which potentially may constitute manipulation or indoctrination. All issues that do not count as controversial should, if they are taught, be taught directively, i.e. with a clear intent to compel belief. A variety of different criteria have been developed to distinguish between controversial and non-controversial political issues (such as behavioral, politically authentic, political and epistemic criteria), which allow for a more or less inclusive array of controversial topics. According to the epistemic criterion, for instance, an issue should be treated as controversial if different epistemically reasonable positions exist with respect to it, that is, positions which are rationally defensible because backed up by sound arguments and justifications as well as by (the best possible) forms of empirical evidence (Dearden 1981; Hand 2008; Tillson 2017). As Hand and Levinson put it: "To teach something as controversial is to teach it as unsettled, to present it as a matter on which contrary views are or could be held. [...] From the fact that a question happens to occasion dispute in some quarters, it does not follow that it should be taught as controversial: there may be an entirely satisfactory and well established answer to the question, of which some parties to the dispute are simply ignorant" (2012: 618). Each of these criteria has been the object of extensive criticism and hence there is considerable theoretical disagreement concerning what should be taught as controversial. We cannot discuss the different criteria brought forward in the debate in detail here. It is important to note though that a central difference between our framework and most other approaches to the 'what' question, is its pluralistic orientation. Instead of relying on a single criterion, our framework is based on a coupling of a political and a science-oriented criterion, which can be formulated as follows (see for a more extensive discussion: Drerup 2021):

1. A question discussed in the political public sphere should be considered controversial in the classroom, if no clear answer can be derived with reference to it on the basis of fundamental political values (i.e., equal rights and freedoms codified in the constitution; personal and political autonomy, value pluralism), which can be considered constitutive for enabling a good personal and political life in liberal-democratic states.

2. A politically relevant issue should be considered as a controversial issue, if there are different reasonable, i.e. well-founded and (as good as possible) empirically substantiated views on this issue and if it is considered genuinely controversial in the relevant scientific disciplines - according the specific methods and argumentation standards, bodies of knowledge and forms of reflection peculiar to these disciplines. Teaching controversial topics should therefore be oriented at the 'the intellectual life' (Yacek 2020) and the associated expertise (Tillson 2017) of scientific disciplines. ${ }^{6}$

\footnotetext{
${ }^{6}$ Both criteria - as equally important criteria - are in principle mutually supportive in their validity, which need not a priori exclude the need for situation-specific prioritizations. They are not to be understood as schematized interpretative templates that enable comprehensive interpretations and evaluations of pedagogical situations and normative
} 
Based on these criteria, a topic such as climate change, for instance, should not be discussed as controversial according to the science-oriented criterion when it comes to the scientific question whether anthropogenic climate change exists at all. What follows from this fact in political terms, however, cannot be easily derived from the political criterion, since there are many reasonable different political positions on how to react to climate change. Coupling these two criteria is linked to our answer to the 'why' question. Focusing on these criteria serves the dual aim of epistemically civilizing the way students deal with controversial issues to counteract a politically motivated subordination of reality (McIntyre 2018) (i.e. by distinguishing between political-normative and empirical issues and limiting, what counts as a well-founded epistemic justification and what does not; for example, 'I just feel that way') and a political civilizing of the way students approach political relevant issues (by clarifying and enforcing the limits of tolerance and pluralism in a liberal democracy, and not in terms of a lazy subjectivism: 'there are just different perspectives'). This dual - science-oriented and political - orientation therefore does not lead to skepticism with respect to moral issues, as Hand objects to political criteria (2008), since rational argumentation and the defense of fundamental values are not mutually exclusive. This answer to the 'why' question assumes that important aims of democratic education such as political tolerance, personal and political autonomy (political criterion) and scientific literacy (science-oriented criterion) should be both cultivated when dealing with controversial issues in the classroom.

These answers to the 'what' and the 'why' question do not automatically imply a clear-cut answer to the question of how to practically deal with controversial issues in the classroom. The road from general justifications and criteria to determine what should count as controversial to educationally and politically sound recommendations concerning appropriate ways of dealing with controversies is no simple exercise in deduction. Due to the complexity of educational settings and interaction orders and due to the many contextual factors relevant in dealing with a controversial issue, in the end it is - always - in central respects a question of the phronesis of the teacher to decide what may be the most effective and reasonable way to pursue. Similarly, there is certainly no linear relation between the means and the ends of teaching controversial issues in the sense that the means are implied or determined by the ends (see: Warnick and Smith 2014). Since democratic education cannot be based on a simple educational technology, which would allow us to attribute means to ends and causes to effects in a one-to-one fashion there is no guarantee that the means and methods we choose will always have the intended effects (Brumlik 2018).

A major part of the debate on the practice of dealing with controversial issues focusses on the role and authority of the teacher and the legitimacy and efficiency of methods utilized often based on the distinction between directive and non-directive teaching. Also due to the lack of a linear relation between means and ends, the analytical distinction between directive and non-directive teaching and the educational rationales that underly them, however, cannot necessarily be equated with empirical teaching styles and practices. The distinction, according to Hand, does not describe "a pedagogical method or style, but the willingness of the teacher to endorse one view on the matter as the right one" (2008: 213). Even though directive teaching is thus in principle compatible with, for instance, a more permissive pupil centered approach, there are nevertheless methods and means that count as more directive than others, such as methods of steering or the use of framing effects (Hand 2007).

\footnotetext{
judgements tailored to them, but rather as elements of an orientation framework that describe relevant normative viewpoints, which can, however, be weighted differently depending on the situation (without thereby forfeiting their fundamental, context-transcending validity). This moderate particularist-casuist caveat is directed against the impractical idea of a simple deduction from programmatically postulated criteria, which does not sufficiently take into account relevant contexts of application and reception and associated dilemmas. This does not imply abandoning claims to cross-domain and cross-subject validity and applicability of the criteria, which need by no means be contrary to a domain- and subject-specific specification.
} 
The interesting point we want to emphasize is that despite the rather loose coupling between educational aims and educational methods and practices in dealing with controversial issues and despite the widespread consensus that some form of phronetic approach is crucial in dealing with controversial issues, it is rather surprising that the default option that is more or less taken for granted in the debate remains some form of discussion (which may vary in style with respect to the specific educational means and teaching styles employed and may be adapted to relevant contextual factors). It seems that major parts of the theoretical discussion about the practice of teaching controversial issues are not about the questions whether discussion itself is an appropriate educational method, but rather about what type of discussion is the most appropriate approach, and what subordinate actions are needed to support these discussions. While a contextualist, casuistic and sometimes also radically particularistic (Saetra 2019) approach is quite common in the debate when it comes to the 'what' and the 'how' question, when it comes to the latter this seems often to be the case only on a superficial level. As soon as it is established that an issue should be taught as controversial it is usually regarded as rather uncontroversial that discussion of some type is the natural way to proceed. Thus, despite the significant variation in what counts as a controversial issue and what makes an issue controversial, in educational discourse a uniform solution to approaching these issues has been presented. ${ }^{7}$ Hand and Levinson sum this up: "[w]ithout exception, as far as we can tell, the contributors to this body of literature hold discussion to be the pedagogical approach most appropriate to the exploration of controversial issues in the classroom" (2012: 614). This focus on discussion as, according to Hand and Levinson (2012: 615), the "optimum pedagogy for teaching controversial issues", itself has to be justified. This is why they bring forward two major rationales for discussing controversial issues: "First, discussion is peculiarly conducive to appreciative understanding of the different positions in a controversy and to empathy to those who hold them" (Hand and Levinson, 2012: 616). Second "controversial issues afford the most promising opportunities for engaging students in discussion" and cultivating "in students the ability and inclination to engage in discussion is itself an important educational goal, and one that can arguably only be achieved by means of teaching controversial issues" (Hand and Levinson, 2012: 617). Even though these rationales are educationally important and in principle sound, we do not think that they suffice to justify the generalist position that discussion should be considered as the default option, unless the meaning of discussion is diluted to mean any sort of interaction between an organism and its surroundings.

The prevalence of a one size fits all approach to teaching controversial issues more or less arbitrarily downplays alternative educational options a priori, which limits the possible ways to practically deal with controversial issues. The narrow theoretical focus on discussions relies on a one-sided normative social ontology of teaching controversial issues, which tends to downplay other crucial components of an educationally sound way of dealing with controversies in practice and as a consequence constitutes a too simple educational approach to complex political questions. Discussions in the classroom do not take place in an educational vacuum but are always already mixed up with and embedded in other educational practices (such as practices of instruction) and arrangements (such as material arrangements that determine the physical position of students or normative arrangements such as curricula, rules etc.), that regulate to a certain extent the way the discussion is realized. This arguably even holds for allegedly entirely 'open' discussions, which cannot abstract from these more or less contingent structural features of the educational constellations in schools. The questions whether discussion is the right method in dealing with controversial issues and when it is appropriate to employ it, thus cannot solely be answered by referring to relevant contextual factors and background conditions such as the knowledge of students or the diversity of their political opinions, but necessarily needs to include a variety of other educational practices, such as practices of inquiry, which should be considered as an essential

\footnotetext{
${ }^{7}$ See, however, for a (rare) counterexample the approaches mentioned in: Ho, McAvoy, Hess \& Gibbs, 2017.
} 
part of teaching controversial issues, not an external add on. Also given the many difficulties and arguably impossibility to make empirically informed - general - normative recommendations of how to handle the many contingencies and non-intended side-effects of discussions (Reichenbach 2020b: 12), we thus should instead focus not just on the adequate educational structuring of discussions themselves and more on other equally important elements of the educational practice of teaching controversial issues.

The advocates of the paradigm of discussion emphasize that the proper preparation, the choice of topics and appropriate facilitation are crucial for the epistemic and also the political quality of discussions (Hand and Levinson 2012; Hess 2002; Hess and McAvoy 2015). We do not just want students to articulate their opinions in the context of discussions, we also want them to provide sound reasons for their opinions which are ideally based one evidence and a proper understanding of the subject matter. The educational and thus epistemic value of discussion essentially hinges on types of educational practices and arrangements, other than the discussion itself. Given that the proper preparation of discussions is absolutely crucial for them to be successful in the first place, these 'preconditions' should in many cases not be interpreted as just facilitating factors for an instrumentally and intrinsically valuable aim (discussion), but instead constitute themselves central components of an educationally justifiable way of dealing with controversial issues, as well as other inquiries. A teacher who, for instance, is considering whether a specific controversial topic should be dealt with in the classroom, not only has to take into account whether her students are appropriately prepared, whether the topic is sufficiently accessible for the students or whether the discussion is structured in an adequate way, she - at the same time and apart from a potential discussion - also has to make sure that - by engaging with the relevant topic - these conditions themselves are taken care of on the basis of adequate methods and realized in an educationally sound way. The immense variation between controversies together with the plurality and internal complexity of practices employed in approaching them successfully, makes it questionable whether the best way to deal with them is to bundle them to into a uniformly solvable bunch subsumed under the notion of 'discussion'.

This does not rule out that discussions are also important and valuable, but it relativizes the prominent and exclusive status of discussions as an allegedly universally relevant solution to the 'how' question, which leaves little room for educational alternatives. Discussion, communication and deliberation are irreplaceable elements of inquiry, and they may be an indicator of a functioning educational situation. Without a doubt, discussions and their effects can include elements (social, affective) that are highly beneficial from an educational perspective and for some students, they might very well be the most memorable or impressive moment of dealing with some issues. Overemphasizing discussion however, carries with it the risk of ending up in such unwanted classroom debates as described e.g. by Oulton et al. (2004: 418): stances are taken before discussion in order to be able to discuss - opinions are locked, and any inquiry to the matter follows only after the discussion, most likely only to prove the chosen stance to be the right one. Such an approach might not be the best way to treat any issues, not least controversial issues, since such practices easily lead to fixed beliefs, not open-mindedness to differing views or possibilities (the very aims of discursive approaches). Nor will such treatment encourage all participants to contribute with their own perspective and intelligence, and it also disregards individual differences in learning styles and the slow nature of learning in complex matters. As we are very unlikely to solve most controversial issues in a satisfying way in a classroom trench debate, nor is that even the right place to solve those issues, the role of discussions in relation to other ways of being informed of the controversy and its components should be reconsidered. Therefore, we should rethink the established assumption that discussion should be considered the - non-controversial - default option. 


\section{Inquiry, discussion, intelligence and democracy}

To provide an alternative framework for dealing with the 'how'-question of teaching controversial issues, we turn to John Dewey's philosophy. Much of his work deals with a dilemma in intelligent action: we need theories and generalizations in order to better function in the varying contexts of our world, but this very variation in the contexts makes most universal theories inevitably inaccurate in the end. What once was an intelligent solution to a problem no longer isn't. The contextuality of all theorization, and the contextuality of all intelligent action on the basis of these theories, points out that when general and universal answers are given to specific and detailed problems, we are closing an inquiry into these very problems, not conducting them (Dewey 1919, 188; see also Kauppi et al., 2020: 48). Our argument proceeds in two parts. First, we clarify what is meant by inquiry ${ }^{8}$ in general in Dewey's philosophy, and what is the role of discussion in inquiry, and secondly, we elaborate the practices of inquiry in education within this framework.

Basing on Ridley's recent account, Dewey's pattern of inquiry may be presented (with a slight risk of oversimplification) in five phases as follows: First phase is the indeterminate situation (1.), feelings of disturbance, ambiguity, conflict or doubt as the situation emerges. The second phase is the problematic situation (2.), as a problem is shaping on the basis of previous experiences. Mode of experiencing begins to shift to that of knowing and observation, as action is suspended and reflection prompted. The third phase is that of suggestions (3.), as suggestions of how to deal with the situation spring up. Ideas begin to form, in order to organize facts, data and/or objects through signs and symbols. Reflecting on, and further examining the conditions of the situation and possible actions taken results in new ideas, which in turn bring new facts, data and/or objects to light. The fourth phase is that of a hypothesis (4.), as a plan of action is created. This plan remains open to revision, in light of following experiences. The fifth phase is that of testing (5.), where the plan of action is executed and tested, and if successful, the outcome is both learning and growth, foresight expanded for similar problems in the future. Reflection and action does seldom proceed straightforwardly as in the pattern, and it is usually necessary to shift back and forth between phases in some points of the inquiry. (Ridley 2020: 44).

According to Dewey, inquiry is to be understood broadly as methods common to all scientific action, applied imaginatively and undogmatically. These methods include (self)criticality, selfcorrectiveness, social (rather than individual) and cumulative formation of knowledge, "considering the realities in terms of cause and effect" and "the working causalities of nature" to produce knowledge to be utilized in "imaginative ventures of invention and construction" (Dewey 1935: 52). Different types of problems demand different modes of inquiry for their solution (Dewey 1938: 82), and the methods of inquiry may be consciously progressed (Dewey 1910: 300). In other words, "scientific methods simply exhibit free intelligence operating in the best manner available at a given time" (Dewey 1938: 529) - it is intelligent action regulated by increasing methods, guiding principles and a community of inquirers, all proven to be useful in making sense of the world. According to the premises pragmatism, also normative and moral issues may (and must) be subjected to test and inquiry, and better and worse solutions can be differentiated. Inquiry in social and moral matters does not mostly differ from inquiry in any other matter: "moral principles are real in the same sense in which other forces are real; that they are inherent in community life, and in the working structure of the individual" (Dewey 1909: 291).

Dewey's thinking bases on a Peircean ontological position which Rydenfelt (2019: 7) describes as hypothetical realism: "In the scientific practice of settling and justifying opinion, the reasons given for and against a belief (often implicitly) make reference to reality: ultimately, a claim is

\footnotetext{
${ }^{8}$ The core of Dewey's notion of inquiry is a conceptual complex, as it has several overlapping concepts, partially due to the long process and different contexts of his ideas taking form. The notion of inquiry here binds together such synonyms as inquiry as "operative intelligence" (Dewey 1938: 524) inquiry as a "scientific method", "reflective thinking" or "critical thinking" (Dewey 1910: 208; 238; 251). See also Ridley (2020: 48), and Narayan (2016: 75-101).
} 
considered to be a reason for or against a belief because it is taken to show how things are or are not, independently of how anyone may believe them to be." But this does not imply that once we find certainty in something, we close the inquiry. "That science may ultimately lead to such conclusions does not tell us how to go about inquiring — it only tells us to keep inquiring." Nor does it mean that we reach the truth as long as we find consensus of how things are and justify it to one another - indeed such has very little to do with how things truly are (Rydenfelt 2019: 9). This stance is tightly bound to the fallibility of all knowledge, "an epistemological position that presumes both the uncertainty (or fallibility) of human knowledge and the possibility of improving our current conceptions (Holma 2012: 397)". Although there are things independent of our conceptions of them, we can never be certain that our conceptions of them are true. It is however desirable to search for conceptions more true than false, to commit to the search for truth, even for practical reasons, as operating on non-factual evidence will not guide us far. ${ }^{9}$

A community is a crucial component of inquiries, which binds discussion to inquiry. "Discussion will bring out intellectual differences and opposed points of view and interpretations, so as to help define the true nature of the problem" (Dewey 1933: 329-330) ${ }^{10}$. In other words, "the plurality of alternatives is the effective means of rendering inquiry more extensive (sufficient) and more flexible, more capable of taking cognizance of all facts that are discovered" (Dewey 1938: 500). Individuals of a community bring in information and possible hypotheses, and direct further inquiries. People's everyday intelligence however is mostly ignored in complicated moral and social matters, in Dewey's view. It is left unnoticed, he claims, that individuals have grown into the meanings of their contexts and their reactions have become intelligent, the social being their natural environment. (Dewey 1916: 282-283; 304; see also Kauppi et al., 2020). People also conduct inquiries into everyday matters very naturally, as the basic pattern of inquiry does not refer to only scientific inquiries, but rather to a wide continuum of intelligent problem solving (Dewey 1938: 106). Training this natural capacity of inquiring is Dewey's answer to making the most of the social intelligence. The value of the intelligence embedded in community members lies in its practical understanding of its own context, as well as in the problem-posing, focusing of inquiries, hypotheses it may provide and the legitimate judging of the decisions made; not in the truth it automatically possesses. And again, the significance and meaning of the hypotheses is not judged solely by the individual behind the hypothesis, but by the community interacting with her. It is not simply up to the individual to decide "who to believe", but the different views should be returned to, and communally reflected again. Being committed to truth rather than justification among peers, the commitment to hypothetical realism, is however of crucial importance in a Deweyan inquiry.

\footnotetext{
9 The plurality of intelligence in thought, variation in perspective and methods included in inquiries does not, however, imply relativism. For that matter, Israel Scheffler's notion of 'plurealism' might offer an additional angle. Scheffler, whose thinking was strongly influenced by Dewey, unites "the realism of C. S. Peirce with the pluralism of Nelson Goodman" (Scheffler 1999: 435). He holds that there are "irreducibly different worlds responding to the variety of statements we accept as true, couched, as these statements are, in the different and unreduced vocabularies we have. We do not [...] make these worlds, but rather live within them, multifarious and independent as they are" (Scheffler 1999: 432). For example, "The sciences of phonology and botany are compatible, but irreducible and they dwell in discrete domains, constituting, if you will, their respective worlds" (Scheffler 1999: 433). However, as Holma (2004: 429-430) notes: "Because plurealism preserves realism, we do not need to think that all systems are equally justified" their justification needs to be examined. Educationally, the import of Scheffler's plurealism is that "we should avoid the idea of reduction, that is, the idea of narrowing or relativizing the richness of human understanding. Educational practice should not be tailored to fit straightforward and oversimple conceptual constructs, such as the scientifictechnical idea of man." (Holma 2004: 430).

${ }^{10}$ However, a Deweyan approach to discussion is far from teaching universal conversational ideals, skills and a spirit of mutual respect. The rules of discussion vary and are negotiated in connection to the context of the discussion. This is well expressed in Dewey's letter to his wife Alice, in which he comments the violent 1894 Pullman strikes and the burnt train cars during them as a necessary means of communication and a "a pretty cheap price to pay - it was the stimulus necessary to direct attention, and it might easily have taken more to get the social organism thinking (Dewey 1894)".
} 
Dewey points out that especially in social matters we often put the horse behind the cart, and do not proceed along the lines and logic of inquiry - it is assumed that "the correct solution is already given and that it only remains to find the facts that prove it" (Dewey 1938: 490). "Social inquiry, in order to satisfy the conditions of scientific method, must judge certain objective consequences to be the end which is worth attaining under the given conditions. But, to repeat, this statement does not mean what it is often said to mean: Namely, that ends and values can be assumed outside of scientific inquiry so that the latter is then confined to determination of the means best calculated to arrive at the realization of such values. On the contrary, it means that ends in their capacity of values can be validly determined only on the basis of the tensions, obstructions and positive potentialities that are found, by controlled observation, to exist in the actual situation" (Dewey 1938: 496-497). This logic is a guiding principle of all inquiries. The controlled observation of the actual situation cannot be only superficial background information for a potential discussion. We need to gather relevant information using varying methods (that do include discussion).

Inquiry is in the Deweyan framework inseparably linked with a democratic way of life. Education is a way to achieve this democratic ideal, as we may (collectively and gradually) learn to be better inquirers, and thus better solve our problems, avoiding the shortcomings of other kinds of societies. In Ridley's (2020: 183) words, "Socialising formal practices of inquiry, developed to sophistication by academics and scientists, would help the public develop its collective intelligence, avoid cooptation by reactionary political parties and interests, free it from the manipulative consumption of the culture industry and, in time, reclaim democracy for the people." It could be argued that the central benefits associated with discussions ("an informed generation of new citizens who can take part in democratic decision making", as Solomon 1992: 442 envisions), remain as an educational aim and a possible outcome, regardless of whether one focuses on either inquiry or discussion. However, the intelligence of the community members cannot be made use of simply by means of communication ${ }^{11}$.

There have been attempts of connecting the deliberative notion of democracy with a pragmatist notion (see e.g. Habermas 2003), but there is a subtle but significant difference between the two, which is essential to our critique: the consensus theory of truth. As Rydenfelt (2021: 242) makes the distinction: "the pragmatist approach to democracy does not rest on the notion of rational consensus". If we take truth and facts as our aims, deliberation or discussion is just not the - only way to go, and with insufficient inquiry the educational and political value of discussions aiming at a concord is questionable in many cases. "Both Dewey and the proponents of deliberative democracy maintain that democracy should be more than the 'majority rule' of ballot boxes; such procedures of representation are often inadequate as means for arriving at increasingly better policies" (Rydenfelt 2020: 35). It still seems that the deliberative take on democracy seems to lead to exactly the kind of problems that follow, when 'the horse is put behind the cart', as it builds on the ideal of equal discussants in a world where such equality is nowhere near, or cannot even be anticipated because of the asymmetric pedagogical relation.

Inquiry is a cyclic process of experimentation. In Rydenfelt's (2021: 244) words: "In Dewey's account, the method of democracy involves not only discussion and deliberation to identify possible solutions, but also the assessment of the outcomes generated by policies tentatively put in place. The public is the central source - we could say, the central data point - for information concerning the outcomes of policy and its desirableness." To better reach this democratic ideal of shared or social inquiry, we need to train the habits of inquiry. That is, it does not suffice that we engage in a rational discussion about matters concerning us, we need to be able to (better) judge the decisions

\footnotetext{
11 As Geuss (2019) points out in his pungent critique: "In some, but by no means all, situations the action in question can take the form of discussion, but there is no form of discussion which is given a priori as ideal. If discussion does not help, as it often does not, one must intervene to change the situation, and the change required may not be the sort of thing those of delicate sensibility automatically welcome. It may be necessary even to use one's hands rather than some purportedly more ethereal organ."
} 
made following these discussions. In order to do this, we need to learn an ethos of inquiry as better solutions and methods for finding them may always appear regardless of our current conceptions, and might even be already possible, although we haven't found it out yet. We need to learn to gather information of the surrounding world and experiences of others in various ways - to listen more, to weigh evidence, to analyse the given situation thoroughly, and to withdraw to reflect and think - that is to inquire. In short, the better we are in our inquiries, the better democracies we may form. Although discussion is in a way or another present in most inquiries, its role and its benefits show in a different light when observed through the notion of inquiry presented. In what follows, we will turn our focus to inquiry as an educational ideal, and its application to controversial issues.

\section{Deweyan inquiry in education}

In "Discussing controversial issues in the classroom" Hand and Levinson (2012: 615-617) argue that it is especially controversial issues, where discussion is the right method: it is futile to spend time discussing matters for which one of the participants (in school, teacher, most of the time) already has the right and undeniable answer. Most mathematical problems are not fertile land for examination through discussion. It is the controversiality of the issues that enables meaningful discussion. Expanding Hand and Levinson's line of argumentation, we suggest that it is controversial, unsettled issues, for which the method of inquiry is an especially suitable approach, and in which inquiry may be meaningfully learned. It is the unsettled nature of the question that makes it possible to engage in a community of inquiry utilizing its intelligence, and not only perform pseudo-scientific tricks or memorize the end products of scientific inquiries. In controversial issues we do not have the definite answers, maybe just some diverse moral convictions, principles, habits and perspectives, and the intelligence of the community members as hypotheses to guide our inquiry - but we also have the world that might be what it is regardless of our convictions and conceptions. The fact that there is controversy around an issue however points to it as being something that we might want to be more extensively informed about to act more intelligently.

How should controversial issues be approached then in education based on a Deweyan notion of inquiry? We start with two cases of 'how not to'. First, Dewey argues that we go easily astray imagining that there is neutral but valuable knowledge of (or inquiry to) the world, for instance the laws of physics, without social meanings embedded in it or strongly connected to it. For example, we don't have to argue whether climate change is true, but to treat it simply as a cold fact with no social meanings connected to it is almost as ignorant as denying the fact. Rather, we should educate people to understand the social meanings of matters traditionally considered as cold facts of science, and why these facts have been sought after and considered valuable (Dewey 1938: 434$435 ; 483$ ). Nor is there intelligence as such that could be taught straightforwardly (see Kauppi 2020: 48-49). Rather we can train habits that may maintain our actions intelligent, such as considering cause and effect, and willingness to learn and to modify old habits (Dewey 1919: 135). In other words, we may train the student's willingness to be informed of their contexts in various ways, and to weigh this information. This information includes their own desires, passions and feelings, along with rational thought (see Bernstein 2006: 172), but to make the most of the varying information, to act intelligently, we need to proceed along the lines best exemplified by the scientific method of inquiry. Although traditionally education stresses the end products of science, understanding of how and why the products have been achieved would be more educative (Dewey 1916: 228-230).

Secondly, there is a danger of misunderstanding with the concept of inquiry (with its connotations to natural sciences), which, when taken to the extremes, has led to such simplified slogan-like pedagogies as "learning by doing" or reducing the meaning of science to mainly natural sciences. In Dewey's educational theory, concrete experimentations in the style of laboratory tests or practical interventions are not per se the point of inquiries. They are necessary rather as effective means to 
develop a better mode of thinking, in which knowing and doing are not dichotomic. This means making scientific thinking, fallibility and logic a part of everyday thinking, and vice versa, taking everyday matters within the spectrum of inquiries (Dewey 1899: 5; 1922: 211). This does not rule out practical experimental interventions in education, but they are not of primary or absolute value, and not everything has to be learned by doing. However, the experimentations, if performed, should not be trivialized to meaningless, ritual-like mimicking of the procedures of science, as often is the case in schools. Focusing on given methods and given solutions differs radically from teaching ways of finding the methods for those solutions. These arbitrary solutions to sometimes irrelevant problems rule out learning to act intelligently and solve the relevant problems of the student's everyday life in ways common to scientific problem-solving. To put these two no's in positive form: the findings of science may well be taught in schools, as long as their social meanings are being explored as well, and as long as the process of these findings becoming a "fact" is being made visible and thus exemplified ${ }^{12}$.

Intelligence, for Dewey, has an ethical component, which links inquiry and the political criterion of controversial issues - that is, if action can be regarded as intelligent, it has to be also morally intelligent (Dewey 1932: 39). Like all natural capacities, intelligence can be trained, and this is the case with moral intelligence too: we become more intelligent in moral matters by engaging in moral inquiries, by exploring the current situation, the possible actions to be taken, and by jointly trying to figure out possible consequences of our actions, to ourselves and to others affected. The limits of inquiry are not set by the object of inquiry - that some things should and could not be inquired - but rather by the relation of the object and the methods chosen. For example, as educators, we might allow a student to inquire whether climate change is real or not, although such might seem objectionable to us, but trusting that inquiry to the matter, if carried out duly, will most likely not lead to a denialist view. The methods chosen for the inquiry will however have to be considered in this case so that minimal harm is done in the course of the inquiry - for example avoiding facilitating such discussions around the topic that could offer possible denialist views undeserved, uncritical and unproportioned attention.

In Dewey's pattern of inquiry, discourse through the use of symbols is employed as a means to overcome the indeterminate situation (Dewey 1938: 109). These are large, compatible yet irreducible webs of symbols, none of which can be regarded as the ultimate set to grasp reality (Scheffler 1999: 432-433). What is in this case also important to note is that not all aspects of reality can be described by linguistic symbols. This Dewey exemplifies by arts ${ }^{13}$ : "If all meanings could be adequately expressed by words, the arts of painting and music would not exist. There are values and meanings that can be expressed only by immediately visible and audible qualities, and to ask what they mean in the sense of something that can be put into words is to deny their distinctive existence" (Dewey 1934: 81). In education we need to guide students to the different sets of symbols that all aim to make sense of the world. The respective import of different sciences and their ways of making sense have to be examined and exemplified, and as Holma (2004: 430) notes, "In addition to the different sciences, for example, the realms of art, morality and religion all belong to education". Thus relevant and comprehensive information may be gathered in all traditional

\footnotetext{
${ }^{12}$ Criticality towards knowledge is an important educational aim. Scientific knowledge for instance must of course be thought of critically, but even more it needs to be taught that we also have good reasons to believe it to be true, even more than to doubt it, exactly because it is openly fallible. The idea of falsifiability, if learned shallowly, will lead to terrible results, if the student's quest for certainty leads them to rely on 'infallible' sources.

${ }^{13}$ To conduct inquiries to the questions of being human, it must be noted that for example arts might have great instrumental value as a part of the imaginative process of inquiry, rather than the methods traditionally seen as more "scientific". By saying this we do not want to diminish any of the intrinsic value of arts, but to note that they can and should be included in the processes that may be termed inquiry - "the controlled or directed transformation of an indeterminate situation into one that is so determinate in its constituent distinctions and relations as to convert the elements of the original situation into a unified whole", as expressed by Dewey (1938: 108).
} 
school subjects or regardless of these divisions ${ }^{14}$. What is needed is not a reform of all practices, rather a slight addition that makes a big difference. Not every lesson can be a full course of inquiry (and doesn't have to be), but traditional lessons can be planned to serve or teach certain aspects or phases of inquiry and a scientific understanding. However, when it comes to controversial issues that require certain sensitivity, it might be good to proceed along the phases of inquiry presented earlier: starting with a genuine indeterminate situation arising from amongst the pupils, carefully reflecting the possible following steps, providing enough time for suspended conclusions (not making too hasty conclusions), and methodological plurality and symbolic presentations from various perspectives, scientific, political, as well as artistic, and maintaining recurring communication during and in between different phases. Even more, it should be held in mind that also such things as painting, music or mathematical formulas can be viewed as forms of fruitful communication.

Inquiry can become a habitual way of approaching the world intelligently, and learned by engaging in inquiries over unsettled issues it can encourage people to engage in common matters by bringing in and developing their intelligence, their information and their hypotheses. At the same time, it might offer - in line with the science-oriented criterion - a fallibilist approach to the world; aid in accepting that one's own knowledge may not be the definitive truth, although it is valuable, and that knowledge yet unknown to us may well exist and must be sought after, as it might be important in regard of the issue at hand. This is an important addition to the aim of learning to live with disagreement and dissent, associated with discursive approaches - learning to live with the fact that we all (not just "the others") may be mistaken about something and need to revise our conceptions. Engaging students with controversial issues in education enables them to exercise their practices of inquiry, which is the core of democratic decision making.

The Deweyan view of inquiry presented offers no clear practical guidelines in the sense of universally applicable pedagogical recipes. Nevertheless, our reconstruction of the Deweyan approach to teaching controversial issues may serve as a theoretical base for further elaborations of different kinds of approaches to controversial issues-education that includes variation in the chosen methods and symbolic presentations, depending on the situation and context, and on the findings of each different and cyclical inquiry. Both in positive and in negative, much rests on an individual teacher's individual power of judgement - taking into account factors such as political polarization, emotional involvement of students, sociopolitical contexts (see also: Pace 2021). ${ }^{15}$ Educational realities take place in constant flux, and this demands fast reactions and constant compromising from the educator (Reichenbach 2020a). The fact that educational practices are complex and quite unstable is a fact we must accept, unless education is degraded into simple memorizing under strict discipline. In such busy settings, the dominant position that discussion now holds (even if the other needed elements are implicitly present in theories of discussion), may lead the educator to stick to it obdurately, on the cost of those other necessary elements of inquiry. Imagine a concrete classroom situation: there's a change in schedule, as some parts of the inquiry to a certain topic turn out to take more time than assumed. Do we then try to rush through these tasks so that we can have the discussion as planned, or do we reschedule the whole process? The answer depends on how much value the educator holds for discussion per se, and how much for (instrumental) discussion that is

\footnotetext{
${ }^{14}$ The fact that educational psychology has differentiated so many different types of learners and learning seems to support this, as we all might gain and process useful information of the matters at hand effectively in very different ways - by reading, discussing, playing guitar or whatsoever.

${ }^{15}$ Many of the changes needed in order for education to reach the democratic goals of politically intelligent citizens through a community of inquiry set demands to teacher training and teacher education. The expectations towards education in solving the problems of the world are immense. The most important concrete demands that the Deweyan approach sets is that we start training teachers guided by a philosophical understanding of science and knowledge production, and an understanding of diverse ways to inquire into a plurality of matters and the plurality of views regarding these matters. Children are naturally provided with a required capability to wonder and inquire - what is needed then is a teacher that may help beyond this good start.
} 
based on a thorough and intelligent investigation of the matter discussed, as well as time to mature our views on base of these investigations. The resulting discussion will certainly be very different, depending on the educator's choice, and this choice will also depend on whether they view the educational process as discussion or as inquiry ${ }^{16}$.

\section{Conclusions}

In this contribution we have developed a critique of the paradigm of discussion as the primary means to deal with the how-question of teaching controversial issues. Simply aiming at discussion should not be understood as a magic bullet in dealing with controversial issues in the classroom, although - depending on the context - it can be a useful method and also a possible sign of a wellfunctioning community of inquiry. To avoid some of the problems of standard - discussion based approaches, a different angle to education as a community of inquiry was presented as an approach to controversial issues in education. The ends and values that discussion as an approach to controversial issues in education strives for, are in our view something that need to be pursued, but the means have to be revised, rescaled and recast in light of their consequences in concrete educational situations.

\section{Acknowledgements}

We wish to thank Professor Katariina Holma and her research group for their comments on the paper, as well as Henrik Rydenfelt for his thoughts.

\section{Funding}

Kauppi's work on this article has been supported by the Finnish Cultural Foundation.

\section{Declaration of conflicting interests}

None

\section{References}

Abrami PC, Bernard RM, Borokhovski E, Waddington DI, Wade CA, Persson T. (2015) Strategies for Teaching Students to Think Critically: A Meta-Analysis. Review of Educational Research, 85(2): 275-314. doi:10.3102/0034654314551063

Bernstein RJ (2006) Richard J. Bernstein's response to Mary Doak. In: Davaney SG \& Frisina WG (eds) The pragmatic century: Conversations with Richard J. Bernstein. New York: SUNY Press.

Brennan J (2016) Against Democracy. Princeton: Princeton University Press.

Bridges D (1979) Education, Democracy and Discussion. Slough, NFER.

Brumlik M (2018) Demokratie und Bildung. Berlin: Neofelis.

Dearden R (1981) Controversial issues and the curriculum. Journal of Curriculum Studies, 13(1): $37-44$.

Dewey J (1894) John Dewey to Alice Dewey, 14 July 1894. John Dewey papers, Special Collections Research Center, Southern Illinois University Carbondale.

\footnotetext{
${ }^{16}$ It must nevertheless be underlined that as there is empirical evidence that meaningful classroom discussions are rather rare (Nystrand et al. 2010, 177) yet promising for promoting such virtues as critical thinking (Abrami et al. 2015), we do encourage all educators to grasp a good discussion whenever there is an appropriate time and space for it.
} 
Dewey J (1899) The school and society. In: Boydston JA (ed) The middle works of John Dewey (Volume 1). Carbondale: Southern Illinois University Press, pp. 1-111.

Dewey J (1909) Moral Principles in Education. In: Boydston JA (ed) The middle works of John Dewey (Volume 4). Carbondale: Southern Illinois University Press, pp. 265-292.

Dewey J (1910) How We Think. In: Boydston JA (ed) The middle works of John Dewey (Volume 6). Carbondale: Southern Illinois University Press, pp. 177-356.

Dewey J (1916) Democracy and education. In: Boydston JA (ed) The middle works of John Dewey (Volume 9). Carbondale: Southern Illinois University Press, pp. 1-370.

Dewey J (1919) Reconstruction in philosophy. In: Boydston JA (ed) The middle works of John Dewey (Volume 12). Carbondale: Southern Illinois University Press, pp. 77-202.

Dewey J (1922) Human nature and conduct: An introduction to social psychology. In: Boydston JA (ed) The middle works of John Dewey (Volume 14). Carbondale: Southern Illinois University Press, pp. 1-230.

Dewey J (1933) How we think, revised edition. In: Boydston JA (ed) The later works of John Dewey (Volume 8). Carbondale: Southern Illinois University Press, pp. 105-352.

Dewey J (1934) Art as experience. In: Boydston JA (ed) The later works of John Dewey (Volume 10). Carbondale: Southern Illinois University Press, pp. 1-453.

Dewey J (1935) Liberalism and social action. In: Boydston JA (ed) The later works of John Dewey (Volume 11). Carbondale: Southern Illinois University Press, pp. 1-66.

Dewey J (1938) Logic: The theory of inquiry. In: Boydston JA (ed) The later works of John Dewey (Volume 12). Carbondale: Southern Illinois University Press, pp. 1-528.

Drerup, J (2021) Kontroverse Themen im Unterricht. Konstruktiv streiten lernen. Stuttgart: Reclam. Englund T (2006) Deliberative communication: A pragmatist proposal. Journal of

Curriculum Studies, 38(5): 503-520.

Levinson M and Fay J (2019) Democratic Discord in Schools. Cambridge, MA: Harvard Education Press.

Geuss R (2019) A Republic of Discussion. Habermas at ninety. In: The Point. Available at: https://thepointmag.com/politics/a-republic-of-discussion-habermas-at-ninety/\# (accessed 19 March 2021).

Gregory M (2014) The procedurally directive approach to teaching controversial issues. Educational Theory, 64(6): 627-648.

Gronostay D (2019) Argumentative Lehr-Lern-Prozesse im Politikunterricht. Wiesbaden: Springer VS.

Habermas J (2003) Truth and Justification. Cambridge: Polity.

Hahn C (1996) Research on issue-centred social studies. In: Ewans, R and Saxe D (eds) Handbook on teaching social issues. Washington: National Council for the Social Studies, pp. 26-39.

Hand M (2007) Should we teach homosexuality as a controversial issue? Theory and

Research in Education, 4(1): 69-86.

Hand M (2008) What should we teach as controversial? A defense of the epistemic criterion. Educational Theory, 58(2): 213-228.

Hand M and Levinson R (2012) Discussing Controversial Issues in the Classroom. Educational Philosophy and Theory, 44(6): 614-628. doi: 10.1111/j.1469-5812.2010.00732.x

Hess D (2002). Discussing controversial public issues in secondary social studies classrooms: Learning from skilled teachers. Theory and Research in Social Education 30(1): 10-41.

Hess D (2009) Controversy in the classroom: The democratic power of discussion. New York: Routledge.

Ho, L, McAvoy, P, Hess, D \& Gibbs, B (2017) "Teaching and Learning about Controversial Issues and Topics in the Social Studies: A Review of the Research," in McGlinn Manfra, M. and Mason Bolick, C. (eds.) The Wiley Handbook of Social Studies Research. Oxford: WileyBlackwell, pp. 321-335. 
Holma K (2004) Plurealism and Education: Israel Scheffler's Synthesis and its Presumable Educational Implications. Educational Theory 54(4): 419-430.

Holma K (2012) Fallibilist Pluralism and Education for Shared Citizenship. Educational Theory 62(4): 637-409.

Huhtala H-M and Holma K (2019) Education of Moral Beings: the Distortion of Habermas' Empirical Sources. Ethics and Education 14(2): 171-183.

Kauppi V-M, Holma K and Kontinen T (2020) John Dewey's notion of social intelligence. In: Holma K and Kontinen T (eds) Practices of Citizenship in East Africa. Perspectives from Philosophical Pragmatism. London: Routledge, pp. 44-54

Kvernbekk T (2012) Revisiting dialogues and monologues. Educational Philosophy and Theory 44(9): 966-978.

McAvoy P and Hess D (2013) Classroom Deliberation in an Era of Political Polarization. Curriculum Inquiry 43(1): 14-47. DOI: 10.1111/curi.12000

McIntyre L (2018) Post-Truth. Cambridge, MA: MIT Press.

Narayan J (2016) John Dewey: The Global Public and its Problems. Manchester: Manchester University Press.

Nystrand M, Wu LL, Gamoran A, Zeiser S and Long DA (2003) Questions in Time: Investigating the Structure and Dynamics of Unfolding Classroom Discourse. Discourse Processes, 35(2): 135-198, doi: 10.1207/S15326950DP3502_3

Oulton C, Dillon J and Grace MM (2004) Reconceptualizing the teaching of controversial issues. International Journal of Science Education 26(4): 411-423. DOI: $10.1080 / 0950069032000072746$

Pace JL (2021) Hard questions: Learning to teach controversial issues. Lanham: Rowman \& Littlefield Publishers.

Parker W (2003) Teaching Democracy. New York: Teachers College Press.

Reichenbach R (2000) „Es gibt Dinge, über die man sich einigen kann, und wichtige Dinge“. Zur pädagogischen Bedeutung des Dissenses. Zeitschrift für Pädagogik 46(6): 795-807.

Reichenbach R (2020a): Bildungsferne. Zürich: Diaphanes.

Reichenbach R (2020b) Grenzen der interpersonalen Verständigung. Gießen: Psychosozial Verlag.

Ridley D (2020) The Method of Democracy. John Dewey's Theory of Collective Intelligence. New York: Peter Lang.

Rydenfelt H (2019) Realism without representationalism. Synthese (2019, Online first). doi.org/10.1007/s11229-019-02251-4

Rydenfelt H (2020) Pragmatism, Social Inquiry and the Method of Democracy. In: Holma K. \& Kontinen T (eds) Practices of Citizenship in East Africa. Perspectives from Philosophical Pragmatism. London: Routledge, pp. 44-54.

Rydenfelt H (2021) Recent Problems of the Public. In: Festl M (ed) Pragmatism and Social Philosophy. London: Routledge, pp. 237-247.

Sanders L M (1997) Against deliberation. Political theory 25(3): 347-376.

Saetra E (2019) Teaching Controversial Issues: A Pragmatic View of the Criterion Debate. Journal of Philosophy of Education 53(2): 323-339.

Scheffler I (1999) A Plea for Plurealism. Transactions of the Charles S. Peirce Society 35(3): 425436.

Solomon J (1992) The Classroom Discussion of Science-Based Social Issues Presented on Television: Knowledge, attitudes and values. International Journal of Science Education 14(4): 431-444.

Talisse R (2019) Overdoing democracy. Oxford: Oxford University Press.

Tillson J (2017) When to teach for belief: A tempered defense of the epistemic criterion. Educational Theory 67(2): 173-191. 
Warnick BR and Smith DS (2014) The controversy over controversies: A plea for flexibility and for "soft-directive" teaching. Educational Theory 64(3): 227-244.

Widmaier B and Zorn P (2016) Brauchen wir den Beutelsbacher Konsens? Bonn: bpb.

Yacek D (2018) Thinking controversially: The psychological condition for teaching controversial issues. Journal of Philosophy of Education 52(1): 71-86.

Yacek D (2020) The criterion of disciplinary authenticity for teaching controversial issues. Unpublished manuscript.

Zimmermann J and Robertson E (2017) The Case for Contention. Chicago/London: The University of Chicago Press.

\section{Author biography}

Veli-Mikko Kauppi is $\mathrm{PhD}$ candidate in philosophy of education at the University of Oulu. He is currently finishing his doctoral dissertation "Education and intelligent action: Deweyan critiques".

Johannes Drerup is professor of Philosophy of Education and Educational Theory at the TU Dortmund as well as a guest professor at the Free University of Amsterdam. His research interests include philosophy of education and childhood, moral and political philosophy and educational ethics. 